\title{
DAS MEMÓRIAS DE NISE DA SILVEIRA NO HOSPITAL PSIQUIÁTRICO DO ENGENHO DE DENTRO
}

${ }^{1}$ Instituto de Antropología de Córdoba, Facultad de Filosofía y Humanidades, Universidad Nacional de Córdoba (ffyh/UNC), Argentina

${ }^{2}$ Consejo Nacional de Investigaciones Científicas y Técnicas (Conicet), Argentina

"Vivo della mia morte e, se ben guardo,

felice vivo d'infelice sorte."

(Michelangelo Buonarroti, 1532)

\section{Introdução}

A psiquiatra alagoana Nise Magalhães da Silveira faleceu no Rio de Janeiro em 1999, quase centenária, por conta de uma insuficiência respiratória aguda. Seu calvário se acumulava desde a década anterior, quando um acidente doméstico a deixara em cadeira de rodas, e se agravara com uma pneumonia contraída em seu último mês de vida. Durante todo esse período, porém, foi acompanhada de perto por uma pequena e sólida rede de amigos e colaboradores.

Alguns desses eram frequentadores das reuniões de leitura abertas ao público mantidas pela médica em sua própria residência, no bairro do Flamengo, no chamado Grupo de Estudos C. G. Jung. Outros concentravam suas atividades na Casa das Palmeiras (CP), situada em um velho sobrado de Botafogo transformado em centro de acolhimento extra-hospitalar a egressos de internações psiquiátricas. Parte deles pertencia à mais célebre instituição fundada pela mestra, localizada no interior do hospital psiquiátrico do Engenho de Dentro. Trata-se do Museu de Imagens do Inconsciente (MII), que desenvolvia práticas clínicas, educativas e museográficas referentes ao binômio arte e loucura. Faziam parte desse conjunto variados atores, entre eles artistas, intelectuais, jornalistas, estudantes, políticos/as, profissionais da área psi, pacientes psiquiátricos, ou simplesmente curiosos/as, sem ocupação definida. 
Nise da Silveira, diferentemente de outros psiquiatras interessados por psicanálise, não chegou a constituir um movimento organizado em torno de seu nome. Nenhuma escola ou doutrina foi proposta ao longo de seu projeto médico-científico, o qual despiu-se de exigências formais ou certificações oficiais. Entretanto, engendrou-se, se não um nisenismo, uma trama de pessoas, instituições e materialidades em torno de sua vida e obra, que persiste até os dias de hoje, mesmo depois de sua morte.

Essas observações permitem entrever a existência de um campo de construção de memória em torno de sua figura, que se faz evidente no presente século e, em particular, na última década. Nele envolvem-se variados agentes, que podem ser classificados em dois grupos distintos: o primeiro, mais reconhecidamente "oficial", inclui seus antigos colaboradores, isto é, as pessoas que se envolveram em seus projetos e que com ela conviveram diretamente; um segundo grupo, que poderia ser caracterizado como "oficioso", é composto por novas gerações de seguidores afetadas pelo trabalho da médica, incluindo-se aí jovens pesquisadores, médicos, artistas e cineastas.

Há diferenças entre os atores comprometidos com essas atividades, entre e dentro de cada um desses círculos. Ao mesmo tempo, todos esses encontram-se dispostos a preservar, difundir e fazer lembrar os saberes e as práticas da psiquiatra nos dias de hoje, compartilhando o interesse por seu itinerário, e materializando-o em políticas públicas de saúde mental e produções culturais diversas. Evoca-se, assim, a tensão entre uma corrente contínua de pensamento, que Maurice Halbwachs (1990) denominou originalmente como memória coletiva, e uma concepção de memória caracterizada pela gestão de contradições e tensões envolvendo um mesmo ator ou vários em relação, como evidente na obra de Michael Pollak (1989). Se nos fundamentos da memória coletiva estão os indivíduos e os grupos situados em espaços e tempos concretos, que a conservam e expressam, em contraste com os esquemas da razão histórica, a memória em si própria é marcada por conflitos, que se configuram entre narrativas, esquecimentos e silêncios.

Com base nesta perspectiva, este artigo apresenta os resultados de uma pesquisa realizada no principal lugar de memória (Nora 1997) relacionado à médica, isto é, o espaço de refúgio e cristalização da memória coletiva, na qual esta passa a ser sustentada deliberadamente em uma instituição pública. Trata-se aqui do hospital psiquiátrico do Engenho de Dentro, antigamente conhecido como Centro Psiquiátrico Pedro II, e desde 2001 denominado Instituto Municipal Nise da Silveira (IMNS). Especial destaque é conferido aos líderes desta instituição que, diferentemente de seus colegas, se apresentam (e são reconhecidos) como empreendedores da memória 
(Jelin 2002) de Nise da Silveira. Lida-se aqui com sujeitos que pretendem o reconhecimento social e a legitimidade política de uma narrativa da trajetória e dos ensinamentos da médica na cena pública, tendo ou não vivenciado a história em questão. Este estatuto se verifica, por exemplo, em sua repercussão midiática, assim como em sua produção bibliográfica e/ou cultural, através das quais se firmam como porta-vozes do tema.

O IMNS, por sua vez, constituiu o mais importante lugar de trabalho de Nise da Silveira durante a maior parte de sua carreira profissional, entre 1944 e 1975, como funcionária pública vinculada à Seção de Terapêutica Ocupacional e Reabilitação (STOR). Nesse âmbito, ficou conhecida por combater práticas biomédicas que considerava violentas (eletrochoque, lobotomia, insulinoterapia etc), ${ }_{1}^{1}$ ofertando em troca atividades expressivas como forma de tratamento para as então chamadas doenças mentais (sobretudo a pintura e a modelagem). A partir desse trabalho, desenvolvido principalmente com base no referencial teórico da psicologia junguiana, passou a agregar uma gama de atores interessada na transformação do modelo vigente de saúde mental. Depois de sua morte, a instituição ganhou particular relevância na construção de sua memória, absorvendo atividades extrainstitucionais (como o grupo de estudos residencial), abrigando seu legado bibliográfico e deixando em menor evidência outros estabelecimentos, como a Casa das Palmeiras, que sobrevive com grandes dificuldades financeiras.

Nos dias de hoje, o complexo chama a atenção por continuar abrigando o MII. O local é mantido por uma pequena rede de profissionais que, tendo colaborado com Nise da Silveira em seu tempo de vida, se destacam como continuadores de seu trabalho, seja nos cargos de direção, curadoria e coordenação, seja no âmbito de práticas terapêuticas. Porém, não existe isoladamente, convivendo também com novos projetos desenvolvidos em referência aos ensinamentos da psiquiatra. Durante o período de confecção da pesquisa, destacou-se o Hotel da Loucura (HL), política pública municipal surgida em 2012, dedicada à oferta de atividades culturais públicas e gratuitas para internos e externos do hospital. Diferentemente do MII, o HL foi fundado por sujeitos que não chegaram a fazer parte das atividades de Nise da Silveira antes de seu falecimento, e que travaram contato com sua obra indiretamente, por meio de estudos e leituras.

Nesse sentido, a partir da atenção comparativa a esses âmbitos, ambos situados no interior do hodierno Instituto Nise, busca-se compreender as disputas pela construção da memória de Nise da Silveira, inserindo-as na configuração mais ampla da história da saúde mental no Brasil. O estudo aponta para uma hierarquia de legitimidade concernente ao contato pessoal com a médica, na qual se forja uma tendência a não respaldar aquilo que 
se diferencia de suas práticas tradicionais. Este diagnóstico, mais que meramente positivo ou negativo, deve inspirar reflexões sobre a continuidade de sua memória no presente século.

Trata-se aqui de um fragmento de uma investigação maior, consubstanciada em uma dissertação de mestrado (Magaldi 2014, 2018a), especificamente dedicada ao estudo do funcionamento do Museu de Imagens do Inconsciente no contexto de desinstitucionalização das políticas públicas de saúde mental no Brasil; e uma tese de doutorado (Magaldi 2018b), voltada para a genealogia de um saber constituído com e através do projeto médico-científico de Nise da Silveira, desde a década de 1940 até os dias de hoje. As duas etapas da pesquisa foram concretizadas por meio de trabalho de campo nas instituições nisianas, incluindo, além de observação participante (realizada em oficinas, reuniões clínicas, grupos de estudos, ciclos de palestras etc), investigação bibliográfica (livros, artigos, entrevistas, catálogos, audiovisuais, teses, dissertações, reportagens, prontuários) e entrevistas semiestruturadas com os colaboradores vivos da médica. O estudo empírico realizado no Instituto Nise se deu entre março e dezembro de 2012, e entre março de 2014 e junho de 2016. Incluíram-se também imersões ocasionais em debates, oficinas e lançamentos de livros e filmes fora desses territórios, abrindo as frestas do hospital. Parte desse material é acionada neste trabalho, sobretudo aquela referente aos atores vinculados ao MII e ao HL.

Neste artigo, optou-se por usar os nomes verdadeiros dos interlocutores, na medida em que constituem figuras públicas que se apresentam em eventos e bibliografias de livre acesso. A investigação foi registrada no Cetape - o Centro de Estudos e Treinamento Paulo Elejalde do IMNS - depois de cadastrada na Plataforma Brasil e aprovada por Comitê de Ética em Pesquisa vinculado à Universidade Federal do Rio de Janeiro. O projeto intitula-se "Nise da Silveira e a genealogia de uma psiquiatria rebelde no Brasil", com número de cadastro CAAE 54861416.7.0000.5582. Agradeço a todos os mediadores que tornaram esta pesquisa póssivel, dentro e fora do IMNS.

\section{Uma trajetória e seus múltiplos}

Nise da Silveira nasceu em Maceió no ano de 1905, filha de uma pianista e de um jornalista e professor de matemática. Com incentivo familiar, graduou-se pela Faculdade de Medicina da Bahia em 1926. Após o falecimento de seus pais, e em meio a dificuldades financeiras, migrou para 
o Rio de Janeiro na década de 1930, ao lado de seu primo e companheiro de vida inteira, o médico sanitarista Mario Magalhães da Silveira. Nessa cidade, chegou a estagiar na clínica de neurologia de Antonio Austregésilo, um dos pioneiros do campo. Posteriormente, foi aprovada em concurso público para trabalhar no Serviço de Assistência a Psicopatas e Profilaxia Mental do Hospício Nacional de Alienados, situado na Praia Vermelha.

Contudo, a médica teve sua atividade interrompida por conta de um acontecimento inesperado. Desde sua chegada à então capital do Brasil, Nise flertava com intelectuais de esquerda e com as atividades do Partido Comunista Brasileiro, embora jamais ocupando sua linha de frente e rompendo com ele em um curto período. Ainda assim, em 1936, às vésperas do Estado Novo, foi denunciada por uma enfermeira pela posse de livros marxistas em seu ambiente de trabalho e encarcerada no presídio Frei Caneca. Somente após um ano e meio foi possível sua libertação, decorrente da inexistência de processo em seu nome. Entretanto, ela se viu obrigada ao exílio no interior do país, que perdurou por quase sete anos, no intuito de evitar novas perseguições. Por conta disso, retornou ao serviço público somente no ano de 1944, com o declínio do regime varguista e a anistia política (Mello 2014; Gullar 1996).

Desta vez trabalhando no hospital psiquiátrico do Engenho de Dentro, para o qual os internos da Praia Vermelha haviam sido recentemente transferidos, Nise tornou-se conhecida por sua contundente crítica de intervenções biomédicas então vigentes, assim como por seu trabalho com atividades expressivas como forma de tratamento em psiquiatria. A militância marxista foi cedendo lugar a um progressivo interesse pela psicologia junguiana e suas possibilidades de aplicação na terapêutica ocupacional. A partir dessa orientação, ensejou a fundação de duas instituições: o Museu de Imagens do Inconsciente, em 1952, e a Casa das Palmeiras, em 1956, além do Grupo de Estudos C.G. Jung, no mesmo ano. Destacou-se, também, período de estudos no Instituto C. G. Jung, em Zurique, a partir de 1957, quando travou contato direto com o pai fundador da chamada psicologia analítica (Villas-Bôas 2015).

Passando por sua aposentadoria compulsória, em 1975, e até 1999, ano em que faleceu, a atividade intelectual de Nise da Silveira foi incessante, incluindo escrita de livros, produção de documentários e curadoria de exposições. Ao longo de quase meio século, seu trabalho atravessou as agitações contraculturais dos anos 1960 e 70, o boom da psicanálise na América Latina e a ditadura civil-militar no Brasil. Já idosa, jubilada e em meio a dificultades de saúde, Nise da Silveira era uma figura pública na cultura brasileira. Pouco antes de deixar a vida, foi agraciada com diversos 
prêmios, entre os quais se destacam variadas medalhas. ${ }^{2}$ Além disso, sobressai-se o título de Honoris Causa pela Universidade do Estado do Rio de Janeiro e pela Escola de Ciências Médicas de Alagoas.

A trajetória de Nise da Silveira se constitui em e através de uma trama que perdura mesmo depois de sua morte, na qual é construída uma série heterogênea de narrativas sobre seu itinerário e seus ensinamentos. Sabe-se, desde a célebre crítica de Pierre Bourdieu (1996) a propósito da ilusão biográfica, dos perigos da produção de uma história de vida como relato coerente, envolvendo uma seqüência de acontecimentos com significado e direção. Não obstante, como alerta Nathalie Heinich (2010), os excessos explicativos da abordagem bourdieusiana geram o risco de invalidar quaisquer relatos com intenção biógrafica, obscurecendo sua compreensão (nos termos da Verstehen weberiana). Nesse sentido, sem a pretensão de sua confirmação ou invalidação, analisem-se aqui, de forma preliminar, alguns aspectos da construção da memória da médica.

O primeiro aspecto, predominante, diz respeito ao enaltecimento da figura de Nise, de seu caráter questionador e da transformação radical do campo da saúde mental decorrente de seu trabalho. Uma célebre entrevista com Ferreira Gullar, na qual a médica narra seu impacto com a agressividade da eletroconvulsoterapia nos anos 1940 e se autointitula rebelde por negá-la, constitui uma de suas principais matrizes.

Paramos diante da cama de um doente que estava ali para tomar eletrochoque.

O psiquiatra apertou o botão e o homem entrou em convulsão. Quando o outro paciente ficou pronto para a aplicação do choque, o médico me disse: Aperte o botão. Eu respondi: Não aperto! Aí começou a rebelde (Gullar 1996:46).

Essa cena e sua qualidade encarnada, a rebeldia, se multiplica em variados meios. São exemplos títulos de biografias, como Caminhos de Uma Psiquiatra Rebelde, de Luiz Carlos Mello (2014), ou o próprio subtítulo do livro de Gullar, Uma Psiquiatra Rebelde. A rebeldia também chega a ser equacionada nos termos de uma revolução, como em manchetes de reportagens: "Quem foi Nise da Silveira, a mulher que revolucionou o tratamento da loucura no Brasil" (Veloso 2017). A repetição dessas figuras leva a crer que as propostas da médica teriam ganhado pleno reconhecimento, sendo incorporadas amplamente em todos os campos sobre os quais estendeu sua influência.

Este aspecto emerge com grande destaque nas associações da médica com o movimento pela Reforma Psiquiátrica (RP) no Brasil, $^{3}$ em que Nise da Silveira se tornou uma referência para alguns estudiosos e militantes filiados ao movimento, que lhe atribuem um estatuto de precursora. Aparecem 
nessas evocações (i. e. Bezerra Jr. 1994; Delgado 2011) a descrição da Casa das Palmeiras como uma espécie de prêambulo dos centros de atenção psicossocial (serviços substitutivos surgidos na esteira da RP), assim como a sugestão de que o contato entre Nise da Silveira e o antipsiquiatra inglês Ronald Laing, que chegou a visitar o MII durante a ditadura militar no Brasil, teria antecipado o trabalho da médica alagoana em relação à luta antimanicomial surgida no período da redemocratização (Silva 2013).

Costuma-se incluir, nessa via interpretativa, dados biográficos que reforçam o aspecto heroico da médica: aquela que, como apontam trabalhos (i.e. Carvalho \& Amparo 2006) foi a única mulher formada em medicina em sua turma de 157 homens na década de 1920, na famosa Faculdade de Medicina da Bahia; aquela que, já no Rio de Janeiro, foi presa e perseguida durante um regime ditatorial; aquela que voltou da clandestinidade e enfrentou os violentos métodos de tratamento vigentes na psiquiatria brasileira no antigo Centro Psiquiátrico Nacional da zona norte carioca. Como certa vez disse um palestrante, ex-colaborador da médica, depois de elencar essa sucessão de feitos grandiosos, o trabalho de Nise "ganhou o mundo". Vê-se, assim, o engendramento de uma narrativa comum, cuja força não provém tanto da racionalidade, mas sim de uma ordem estética e emocional, e que poderia ser caracterizada como uma espécie de mito de Nise da Silveira (L'Estoile 2012).

Ao lado dessa versão enaltecedora, heroica e afetiva predominante em sua biografia, são evidentes as dificuldades vividas pela médica, visto que os conceitos e os métodos que se delinearam ao longo de sua trajetória encontraram grandes dificuldades de aceitação em seu tempo de vida. Depoimentos de aliados da psiquiatra ou dela própria, registrados em livros, artigos e entrevistas, mencionam essas adversidades, incluindo tentativas de sabotagem e silenciamento protagonizadas pela classe médica e/ou por agentes estatais, interna e externamente ao hospício em que trabalhava. Destaquem-se tentativas de fechamento de suas instituições; a depredação das instalações ocupacionais, como o jardim e o ateliê, que chegou a ser preenchido com leitos de internações, e o envenenamento e a morte dos animais coterapeutas que participavam da Seção de Terapêutica Ocupacional e Reabilitação, na década de 1970 (Mello 2014). Conflui nessas tensões uma série de fatores: o incômodo gerado por sua figura feminina, imigrante, nordestina, marcada por uma trajetória política de prisão e exílio sob a acusação de comunismo; a provocação ao saber biomédico hegemônico, portado por seus pares médicos; e o modo particular de tratar corpos considerados menos importantes na escala de distribuição de humanidade 
que ganhava forma na terapêutica ocupacional, como pacientes psiquiátricos e, além destes, animais como cães e gatos, acionados como coterapeutas (Magaldi 2018b).

Em seu mais importante livro, Imagens do Inconsciente, a própria psiquiatra menciona o desprestígio de suas propostas diante da predominância dos métodos de tratamento fisicalistas (além das já referidas, destaquem-se os medicamentos psicotrópicos, surgidos a partir da década de 1950). Nessa configuração, reforçada em uma tradição cultural que desvaloriza os trabalhos manuais, o uso de atividades expressivas por agentes terapêuticos seria logicamente considerado ingênuo e quase inócuo, valendo, quando muito, para distrair os internos ou torná-los produtivos com respeito à economia hospitalar. Como chegou a afirmar: "Minha orientação quebrava velhos preconceitos, e era demasiado ambiciosa, ao pretender que a terapêutica ocupacional fosse aceita, se corretamente conduzida, como um legítimo método terapêutico e não apenas uma prática auxiliar e subalterna" (Silveira 1981:30). Ademais, em seus relatórios, Nise sublinha, além de falta de pessoal, deficiência de verbas e superlotação hospitalar, o fato de que, no âmbito nacional das políticas públicas de saúde, seu trabalho tampouco vingou, dissolvendo-se em diversas tentativas falhas ao longo de sucessivos governos. Por fim, diagnostica a cisão entre seu trabalho e a medicina: "Revendo nossos relatórios anuais encontramos, como um leitmotiv melancólico, a menção de que não lográvamos articular a seção de terapêutica ocupacional com os serviços médicos" (Silveira 1979:23).

O leitmotiv melancólico, êmico aos próprios ditos e escritos de Nise da Silveira, aparece aqui e ali em alguns atores, que sublinham o caráter problemático de uma memória mítica de Nise da Silveira através da referência a aspectos subterrâneos de seu legado. Márcia Cunha (2008), psiquiatra e ex-diretora do MII, sustenta que, na verdade, os conceitos introduzidos por Nise da Silveira não foram absorvidos no meio psiquiátrico contemporâneo, inclusive aqueles comprometidos com os valores e as práticas reformistas. Em sua leitura, a afirmação de que o modelo de abolição das internações com ênfase na ressocialização seria consequência direta do projeto médicocientífico da médica alagoana seria improcedente. Isto porque, na prática, seu método - que preconiza a produção plástica espontânea seguida do estudo das imagens, através da valorização da individualidade - não seria plenamente seguido nas políticas de saúde mental, ficando inclusive em segundo plano em relação a autores europeus. Comparando o modelo antipsiquiátrico e o método de Nise, afirma: "na realidade, não há identidade entre ambos, sendo coisas totalmente distintas" (Cunha 2008:16). 
Na mesma linha, Walter Melo - ex-colaborador de Nise da Silveira, professor e pesquisador da área de psicologia - critica como essa associação, a seu ver inadequada, é delineada dentro do próprio grupo de colaboradores mais próximos da médica. De acordo com o autor, a repetição das histórias contadas pela própria Nise da Silveira da parte de seus (per)seguidores tem o negativo efeito de torná-la um ser predestinado e a-histórico ou, mais precisamente, um ícone. O tempo transforma-se num ciclo que se fecha e se explica sobre si próprio, isto é, torna-se um tempo mítico. A médica passa a ser enaltecida como pioneira nas ideias da Reforma Psiquiátrica, sugerindo identidades entre práticas e saberes díspares, e conduzindo a história de uma maneira a-histórica: "É como se os trabalhadores de saúde mental contemporâneos dissessem: o importante trabalho que fazemos atualmente já era feito há muito tempo por Nise da Silveira, mesmo que ela não soubesse disso (Melo 2007:110).

Chega-se, assim, ao diagnóstico de uma biografia de glória, afetiva, contrastada pela ponderação racionalizante das especificidades e falhas de seu trabalho. A seguir será demonstrado como esses eixos de cristalização da memória de Nise da Silveira não são exclusivos de determinados círculos, fazendo-se presentes em toda a trama de relações envolvida no campo investigado.

\section{O Museu de Imagens do Inconsciente}

No bairro do Engenho de Dentro, na zona norte do Rio de Janeiro, um quarteirão inteiro é cercado por uma longa cadeia de grades esverdeadas, sendo atravessado apenas por um turvo canal. Em suas margens, na extensão de aproximadamente 8 mil metros quadrados, situa-se um complexo hospitalar centenário destinado à oferta de serviços de atendimento médico e assistência social, com particular destaque para a saúde mental. A instituição tem sua principal entrada na rua Ramiro Magalhães, n. 521, onde uma guarita, sempre acompanhada por seguranças, solicita a identificação de seus visitantes. No muro, flores azuis sustentam um desenho com o nome Nise da Silveira, que desde 2001 batiza a instituição, o atual Instituto Municipal de Assistência à Saúde Nise da Silveira.

Na outra extremidade do terreno há ainda uma segunda entrada, menor e mais escondida, situada na rua Bernardo. Nesta, há uma porta gradeada que, embora permaneça trancada a maior parte do tempo, pode ser facilmente aberta caso se faça o pedido a um porteiro através da fresta. Feita a travessia, já dentro do instituto, logo se está diante de um prédio verde e branco, de 
dois andares, discretamente ornamentado com algumas estrelinhas coloridas à esquerda. À direita, uma placa explicativa diz Museu de Imagens do Inconsciente, seguida de um texto que, mais uma vez, menciona a alcunha implicada na nomenclatura do estabelecimento.

Criado em 1952 pela doutora Nise da Silveira, reúne trabalhos de terapia ocupacional produzidos pelos frequentadores do instituto [...]. Diretamente vinculado aos ateliês de pintura e modelagem da instituição, o museu recebe a cada dia novos documentos plásticos que formam um acervo estimado em 350 mil obras.

O visitante que hoje cruzar os portões do IMNS se depara prontamente com a douta imagem fotográfica da médica, ocupando o primeiro painel da mostra intitulada A Emoção de Lidar, levada a cabo no MII. Disposto sobre uma parede cuja fronte se dirige à porta de entrada, o elemento abriga um retrato ampliado da personagem. Ainda jovem, ela se apresenta com um olhar severo e um vestido formal. Ao lado, um texto, com suas próprias palavras, registra a famosa cena de seu encontro com o eletrochoque, reproduzida acima na citação de Ferreira Gullar (1996).

O MII é o mais conhecido estabelecimento fundado por Nise da Silveira por ter sido a primeira das duas instituições nas quais se envolveu, e sobretudo por funcionar até hoje como espaço de zelo da sua obra através de seus colaboradores vivos. Atualmente, o lugar mantém em pleno funcionamento uma série de atividades, dentre as quais se destacam três: 1. O grupo de estudos aberto ao público, realizado regularmente nas manhãs de terças-feiras. A atividade é quase sempre organizada no formato de aulas ou palestras proferidas pela equipe de funcionários ou por profissionais convidados para quaisquer interessados; 2. O espaço de exposições, que conta com visitas guiadas, assim como a reserva técnica, que mantém a guarda do acervo pictórico sob o zelo de uma equipe de museólogos e estagiários; 3. O ateliê de pintura e modelagem, que opera atendendo a usuários da rede de saúde mental carioca, hoje em sua maioria externos à enfermaria do hospital. A equipe clínica conta com uma média de dois estagiários de psicologia (itinerantes), além de uma psiquiatra, uma arteterapeuta, uma assistente social, entre outros. Mais que uma escola de arte, trata-se de um espaço terapêutico destinado à expressão espontânea, cujos resultados permanecem na instituição para fins de arquivamento e estudo psicológico. A instituição conta ainda com a Biblioteca Nise da Silveira, herança do conjunto bibliográfico pessoal da médica.

Entre sua diminuta equipe de profissionais, em sua maioria funcionários públicos do município, destaca-se seu diretor e curador, Luiz Carlos Mello. Em suas palestras, realizadas no MII, pôde-se entrever sua trajetória em 
seus próprios termos. Lula, como é conhecido, conheceu Nise da Silveira nos anos 1970 durante as reuniões do grupo de estudos aberto ao público realizado no apartamento da psiquiatra, na rua Marquês de Abrantes. Nessa época, ele era um jovem estudante de engenharia da UFRJ. Logo deixou os planos de seguir na profissão para trabalhar voluntariamente ao lado de sua mestra no Engenho de Dentro, e nunca mais interrompeu sua atividade. Hoje se dedica principalmente aos aspectos museográficos da instituição, montando suas exposições e estabelecendo seus circuitos e sua divulgação junto à equipe de museologia. Ele também é o profissional responsável pela biblioteca, que funciona como seu gabinete de trabalho.

A trajetória de Lula encontra-se em seu livro, a fotobiografia Nise da Silveira - Caminhos de Uma Psiquiatra Rebelde (Mello 2014). Trata-se de uma biografia ilustrada de Nise da Silveira, construída a partir de uma extensa série de documentos, tais como fotografias, cartas, manuscritos, textos e entrevistas, em sua maioria parte do acervo pessoal da psiquiatra, que chegou a ser contemplado pelo Programa Memória do Mundo da Unesco com o título de Patrimônio Documental da Humanidade, e que permanece sob a guarda privilegiada do MII. Na obra, o diretor explica seu contato pessoal com a médica através da narrativa de um sonho irresistível, no qual Nise da Silveira demonstrava a necessidade de colaboradores para o desenvolvimento de seu trabalho: "Chamou os participantes do grupo para conhecê-lo [seu trabalho], dizendo que a psicologia junguiana estava viva em Engenho de Dentro e não apenas nos livros que ali estavam sendo estudados" (Mello 2014:36).

Em entrevista, Nise admite a importância de Lula para seu trabalho, argumentando que a maioria dos frequentadores do grupo de estudos não chegava a conhecer de perto o Engenho de Dentro. Lula foi uma feliz exceção.

Eu sempre digo: a psicologia junguiana não está aqui na sala, está em Engenho de Dentro. E foi assim que o Lula foi a Engenho de Dentro. Aqui é conversa, teoria necessária, mas o âmago está é lá. E Lula, que acabara de fazer vestibular para engenharia, foi e ficou (Silveira 1994).

Vê-se que Lula conquistou Nise sobretudo a partir de sua entrega voluntária ao trabalho, inicialmente como estagiário, e de sua capacidade intelectual, afinada com as ideias da psiquiatra: "É [ele] quem lê muito bem as imagens. Tem dado uma ajuda inestimável [...]" (Silveira 1994).

De maneira mais discreta, outros profissionais se agrupam ao lado de Lula. Gladys Schincariol, que conheceu a médica no mesmo período, encarna a dimensão mais propriamente terapêutica do museu, coordenando 
as reuniões clínicas derivadas do atendimento oferecido pelo ateliê de pintura e modelagem, e trabalhando diretamente com os pacientes, também conhecidos ali como clientes. ${ }^{4}$ Gladys e Lula são igualmente responsáveis pelo grupo de estudos, que conta com a presença de profissionais convidados que realizam conferências regularmente. Entre estes, destacam-se Eurípedes Cruz Junior, pesquisador, antigo vice-diretor da instituição e atual coordenador da seção de esculturas do Museu Nacional de Belas Artes e, além dele, Maddi Damião Jr., psicólogo junguiano e professor de psicologia da Universidade Federal Fluminense. Ambos foram colaboradores de Nise da Silveira em seu tempo de vida. Eram, mais que discípulos, os continuadores do trabalho da psiquiatra, tal como sugeriu certa vez a coordenadora durante umas das reuniões do grupo. Com sua presença, evidenciava-se o privilégio do contato pessoal com a médica, que se manifestava nas apresentações.

Foi através das portas do MII que tive o primeiro contato com Nise da Silveira e os vislumbres da persistente memória da psiquiatra. Comecei a frequentar o lugar regularmente em abril de 2012, por ocasião de uma pesquisa de mestrado que, baseada na observação participante, se concentrou principalmente no ateliê de pintura e modelagem, no grupo de estudos e nas reuniões clínicas (Magaldi 2014, 2016, 2018a). Foi nesse processo que, de forma ainda tímida, comecei a engendrar uma inquietude sobre a memória de Nise da Silveira, que era evocada tanto por terapeutas quanto pelos próprios pacientes e demais frequentadores daquele lugar no curso de suas atividades, muitas vezes como se de algum modo a psiquiatra estivesse ali.

Como me explicava sempre um cliente enquanto pintava: "para a Doutora Nise, não importa se é bonito ou feio... o importante é passar do inconsciente para o consciente". Via-se que seus ensinamentos lhe pareciam caros e eram referenciados no tempo verbal presente, mais que no pretérito. Isto, ao longo do trabalho de campo, não era um caso isolado e se verificava também entre equipe terapêutica, a qual suscitava a presença da psiquiatra. Certa vez, uma monitora, chamando a atenção para a proximidade excessiva dos clientes na mesa de trabalho, disse: "Doutora Nise jamais concordaria. Como é que vão revelar o inconsciente assim, com um em cima do outro"? Daí, surgia a suspeita de que, para aquele grupo, a recordação de Nise da Silveira estabelecia uma continuidade substancial entre o hodierno e o pretérito, e que a fidelidade a seus métodos se apresentava como um imperativo.

Além do ateliê, era no grupo de estudos que a referência a Nise da Silveira ocorria com mais frequência. Este espaço, situado em um grande salão retangular do segundo piso, era ocupado pela mesa de trabalho que, 
como seus organizadores sempre gostavam de lembrar, havia pertencido à própria médica. Apresentava-se ali com paixão sua obra, incluindo citações de seus dois principais livros, Imagens do Inconsciente (Silveira 1981) e O Mundo das Imagens (Silveira 1992), assim como alguns dos 15 documentários científicos realizados entre 1981 e 1986 por Nise da Silveira em parceria com seus colaboradores mais próximos, sintetizando as principais pesquisas sobre as obras dos frequentadores do ateliê. Era quase exclusivamente através dessas fontes que sua memória se atualizava: fontes externas, não oficiais - como, por exemplo, biografias produzidas por jornalistas (Horta 2008) ou pesquisadores que não chegaram a conhecer a psiquiatra pessoalmente (Pompeu \& Silva 2013) - não costumavam ser citadas. O conteúdo das palestras, proferido pelo diretor, pela coordenadora ou pelos convidado, se embasava principalmente na reiteiração das histórias dos pacientes mais célebres de Nise da Silveira, que ganharam repercussão no campo artístico carioca em meados do século passado, e que faleceram em sua maioria na década de 1980. Menor atenção era conferida aos clientes contemporâneos da instituição, embora eles estivessem presentes no grupo como ouvintes e comentaristas. No final da pesquisa, porém, este quadro se reverteu, com uma mostra sobre a atual produção do ateliê.

Entretanto, o interesse pela atualidade também se fazia presente ali. Luiz Carlos Mello costumava proferir as conferências de abertura e de encerramento dos seminários. Nessas ocasiões, seu discurso versava frequentemente sobre a trajetória de Nise da Silveira e sobre as origens do MII, sublinhando o pioneirismo da médica na crítica à psiquiatria clássica. Um ponto frequentemente suscitado era a afinidade de Nise da Silveira com a Reforma Psiquiátrica no Brasil. Para o diretor, o processo de desconstrução do lugar das internações manicomiais teve suas origens na experiência de Nise da Silveira em meados do século passado. Caçada na conjuntura política do Estado Novo, a psiquiatra viu no hospital uma instituição análoga ao presídio, dadas as estruturas repressivas desses lugares. O método encontrado por ela para combater o isolamento foi negar o eletrochoque, promovendo, ao invés, atividades expressivas, com o objetivo de "penetrar no mundo interno" de seus pacientes. Para ele, este método estaria "em conformidade com a luta antimanicomial".

Outro ponto frequentemente retomado pelo diretor era a aposentadoria compulsória de Nise da Silveira, que se deu no ano de 1975, quando a médica tinha 70 anos. Nessa fase, formou-se o grupo de herdeiros de seu legado, que inclui o próprio diretor, a coordenadora de projetos da instituição, seu antigo vice-diretor, além de profissionais engajados em outras atividades terapêuticas, artísticas e políticas externas ao MII. Na mesma ocasião 
afirmou a coordenadora: "Desde então, o museu mudou muito. O trabalho é produto de uma equipe ainda muito inspirada na Nise, mas teve que se renovar". Entre essas mudanças, destaca-se o próprio processo de RP brasileira.

Não atendemos muita gente. É um trabalho de dedicação, que recebe clientes de centros de atenção psicossociais, de enfermarias, e demais frequentadores referendados a outras instituições. É um trabalho de corpo a corpo, com uma pequena clientela. A atividade expressiva é uma das fontes, mas o objetivo é a liberdade, a desinstitucionalização.

Nota-se, a partir de falas como esta, como esses agentes buscam atualizar o próprio método de Nise da Silveira para os dias de hoje e, ao mesmo tempo, afirmar sua permanência e vanguardismo.

Uma ocasião interessante nesse sentido se deu quando, a convite de Schincariol, apresentei meu próprio trabalho em uma das reuniões do grupo. Não era comum que palestrantes externos ao grupo já referido fossem convidados. A palestra buscava demonstrar as diferenças entre os métodos de atividade expressiva preconizados no MII e nos Centros de Atenção Psicossocial (CAPs) surgidos no bojo da RP. Explicava como, no primeiro caso, a produção plástica deve ser espontânea; as obras não podem se vendidas nem portadas por seus criadores, devendo permanecer na instituição museal para fins científicos e psicoterapêuticos (ênfase na dimensão do "inconsciente", psicológica); no segundo caso, diversamente, valoriza-se o ensino da técnica e os critérios estéticos, e as obras devem circular no campo social, para fins de geração de renda, desestigmatização e produção de autonomia (acento na dimensão da "cidadania", relativa aos direitos). O militante antimanicomial Milton Freire, presente na ocasião, confirmou minha proposta, explicando as diferenças entre Nise da Silveira e as maiores lideranças da RP. Enquanto Nise interessava-se sobretudo pelo estudo das imagens do "mundo interno", os militantes reformistas propunham superar o modelo manicomial através do repto de uma "sociedade sem manicômios", mais afim com a psiquiatria democrática de Basaglia.

Entretanto, a maior crítica em relação a meu trabalho veio do próprio Mello. Embora reconhecendo a qualidade da pesquisa, ele sugeriu que a separação radical entre Nise e a RP era insustentável e intelectualista. Com isso, parecia-me, o diretor buscava salvaguardar a importância e o caráter prógono de sua mestra para os subsequentes desdobramentos da história da saúde mental brasileira, o que era questionado na apresentação dos resultados do estudo. Para exemplificar seu argumento, leu um trecho de sua recém-lançada fotobiografia, em que citava as palavras de Nise: "Uma 
das críticas feitas ao museu é a de que se ocupa demais do mundo interno e abandona o externo, esquecendo-se que um responde ao outro [...]. Há sempre uma inter-relação entre o interno e o externo" (Silveira citada em Mello 2014:227).

Respondi que, de fato, tratava-se de uma atitude do intelecto. Seu objetivo, porém, não era o de reduzir, mas de complexificar as discussões sobre as relações entre arte e loucura na saúde mental brasileira. Para isso, repliquei com outra citação: uma entrevista com Nise da Silveira, na qual diferenciava sua proposta daquela de Franco Basaglia, considerado líder da reforma psiquiátrica na Itália e de grande influência no Brasil: “O movimento Basaglia, que eu aprecio, e estou de acordo de que estes velhos manicômios que se parecem prisões sejam implodidos, é um movimento que a meu ver não se ocupa do mundo interno do paciente" (Silveira 1994:1). Com isso, queria dizer que as propostas (de Nise e da RP) eram sim diferentes, mas não propriamente incompatíveis.

A questão ficou em aberto. A despeito dessa ocasião, não se chegou a criar um clima de hostilidade, mas sim o reconhecimento de uma diferença de interesses e posições, isto é, de distintos regimes de memória. A sustentação do pionerismo de Nise, presente no discurso de Lula e respaldada por seu espaço institucional, se contrabalançava com minha pesquisa acadêmica, dirigida no sentido racionalizante de "separar o joio do trigo", como cheguei a afirmar.

Além do grupo de estudos, outro locus de concreção da memória da médica se encontrava na Biblioteca Nise da Silveira, que passei a investigar com mais atenção durante o doutorado (Magaldi 2018b). O acervo bibliográfico se encontra no segundo andar do MII, em frente à sala da coordenação, onde acontecem as reuniões clínicas. Trata-se de um pequeno ambiente dividido em dois cômodos. O primeiro, uma espécie de antessala, conta com uma mesa de trabalho, na qual permanece um bibliotecário, e uma vitrine em que figuram algumas das principais obras e catálogos de Nise da Silveira. Entre estes, a fotobiografia de Mello.

Entretanto, nenhum processo classificatório foi até agora realizado sobre o conjunto, que inclui tanto os trabalhos de Nise da Silveira quanto livros que ela própria possuía, além de periódicos editados pelo antigo grupo de estudos. O acervo conta com o total de 60.000 itens entre livros, livretos e periódicos, contendo obras do final do século XIX aos anos iniciais do século XXI. Porém, logo em minha primeira visita à Biblioteca, descobri que o visitante que quiser consultar o acervo deverá, de antemão, saber o que deseja buscar e fazer a solicitação pessoalmente ao diretor, única pessoa a saber, par coeur, a localização exata de cada obra. A figura do bibliotecário, 
ali, aparecia mais como a de um secretário ou zelador do que a de alguém responsável pela organização das obras. Em certo sentido, Lula era o próprio arquivo, na medida em que, na ausência de um sistema classificatório, era ele quem concentrava o conhecimento sobre o material, na condição de guardião da memória. Nesse sentido, a passagem da memória para a história, que depende da abertura de um documento à total e livre consulta (Pomian 1997), encontrava ali um intervalo.

Conversando com o bibliotecário e com o diretor, tomei conhecimento do descaso do poder municipal do Rio de Janeiro, que mantém a instituição em grandes dificuldades financeiras e com um corpo reduzido de funcionários, impedindo a contratação de um profissional de arquivologia para a organização sistemática do acervo literário. O local ainda padece de problemas como infiltrações, insetos e demasiada incidência de luz, prejudicando a estrutura de alguns fascículos. O leimotiv melancólico aparecia aqui através da gramática da precariedade, designando uma assimetria de poder entre a instituição e o poder público mais amplo.

Não obstante, entre as consequências dessa condição de escassez, constitutiva de um quadro oficial da memória, está o fato de esta, tal como produzida no MII, existir na tensão entre o caráter do documento, isto é, daqueles instrumentos destinados à visibilização e ao ensino de forma clara e disponível, e do monumento, ou seja, daqueles artefatos que evocam e fazem lembrar de maneira mais intuitiva que instrutiva (LeGoff 1984). A biblioteca, dada a ausência de sua arquivologia, se inscreve nesse fio tênue. Este espaço é marcado com o acesso restrito e mesmo com ares de mistério, tendo sua inteligibilidade filtrada em relação ao público mais amplo, acadêmico ou não. De outro modo, ambientes como o grupo de estudos e o espaço expositivo encarnam a dimensão da difusão do saber em seu aspecto pedagógico, desimpedido e, portanto, documental. É neles que os ensinamentos de Nise da Silveira são exibidos mais notoriamente através de conferências e visitas guiadas protagonizadas pela atual equipe técnica, por sua direção e coordenação.

Nise, vê-se ali, apresenta-se em diferentes camadas de evidência, nas quais alguns personagens, como Mello, se tornam sua própria memória viva. Último exemplo disso é sua participação como consultor na produção do filme Nise - O Coração da Loucura, de Roberto Berliner (2016). A película, que retrata o retorno da médica ao serviço público na década de 1940, foi filmada em parte no próprio IMNS, além de ter sido baseada em pesquisa realizada exclusivamente com os colaboradores mais diretos. A memória, aí, encontrava sua variação oficiosa, com alguma ficção, mas não constituía propriamente uma traição, sendo, ao contrário, retroalimentada por suas 
variações mais oficiais. Assim, diz o diretor do filme em entrevista: "Os atores [...] foram conhecendo mais através de pesquisas no Museu de Imagens do Inconsciente. Luiz Carlos Mello deu aulas para os atores que interpretaram os clientes sobre cada um dos personagens reais" (Berliner 2016:s/p).

\section{O Hotel da Loucura}

No primeiro ano de pesquisa, enquanto acompanhava as atividades do MII, ouvia reações controversas a uma novidade surgida a poucos metros de sua sede. Era o chamado Hotel da Loucura. Alguns profissionais afirmavam que as suas atividades - focadas primordialmente no teatro, mais do que na pintura e na escultura - agitavam os pacientes. "Nós temos que fechar as feridas que eles abrem", diziam-me em tom condenatório. Para seus críticos, era como se o HL fizesse um mau uso das ideias de Nise da Silveira, exagerando suas propostas em detrimento de um acompanhamento clínico mais rigoroso, incluindo mesmo a manutenção necessária de alguma distinção ou hierarquia entre monitores e clientes. Para outros, no entanto, a diferença poderia ser encarada de uma forma mais analítica, e não tão crítica. "O foco do Museu é o mundo interno. No Hotel, eles trabalham o mundo externo", me explicou Milton Freire, ex-cliente de Nise da Silveira e militante antimanicomial que frequentava ambos os lugares. Foi justamente essa tensão, expressiva das tensões em torno da memória e dos ensinamentos da médica, que motivou a extensão da pesquisa aos domínios dessa política pública.

O primeiro contato com as atividades do HL foi travado em setembro 2014, já no período do doutorado, por ocasião do Ocupa Nise, evento que abrigava artistas, estudantes e militantes de todo o país. Incluía em sua programação um encontro da Rede Brasileira de Teatro de Rua, além de saraus e oficinas de atividades expressivas, todos realizados no seio do hospital psiquiátrico do Engenho de Dentro e contando com a participação de clientes internos e externos. Nessa ocasião, por volta de 100 pessoas reuniam-se em torno de um pequeno gramado, situado logo atrás do edifício da enfermaria do complexo psiquiátrico. No centro da arena, em um pequeno elevado, Vitor Pordeus, um médico e ator, que coordenava o acontecimento, segurava um microfone, entoando palavras de ordem. Clientes e atores - e era quase impossível saber quem era quem - ouviam suas palavras em clima de animação, entre música e fantasias coloridas.

Na ocasião, uma representação teatral ocupou o centro das atenções. Abriu-se uma pequena roda em cujo centro um homem, vestido com roupas 
de presidiário em tons de laranja, narrava a um pequeno público a história da médica cujo nome intitulava o hospital. Era Nise da Silveira. "Entre 158 alunos, era a única mulher", dizia, em referência à sua formação na Faculdade de Medicina da Bahia, nos anos 1920. "Ela veio pro Rio de Janeiro. Um médico muito bom chegou para ela e disse: vou mostrar a nova técnica maravilhosa que vai curar nossos problemas mentais. O médico pegou um doente". Nesse momento, o ator puxou de forma brusca, pela camisa, outro ator que se encontrava na plateia circundante. $\mathrm{O}$ "médico" pediu para seu "paciente" deitar no chão. "Vou mostrar para vocês, olha que maravilha, o melhor tratamento que tem! Se chama eletrochoque!", gritava efusivamente, em claro tom de cinismo. E, violentamente, colocava as mãos no ator, que tremia descontrolado em seu leito terrestre. Tambores ao redor batiam, nervosos. Sopros de fúria perpassavam a banda de metais. Era arrepiante. "Não tá bom, não? Vou de novo!". E encenava insaciavelmente a aplicação do choque. "Está mais calminho? Não! Precisa de mais! Mais!!!'

Em seguida, o ator-médico dirigiu-se a uma mulher que entrara no círculo. Era uma atriz no papel de Nise da Silveira. 'Você vai apertar o botão ou não vai?', perguntava o "médico" à moça. "NÃO!", respondia com força. "Vai apertar ou não vai?", perguntava de novo, mais alto, sem desistir. E a atriz gritava ainda mais forte e resistente: "NÃO!!! NÃO!!!! NÃO"!!! E todo o público fazia coro com a sua negação. "NÃO! NÃO! NÃO! Em todas as paredes do hospital, ecoou o não"!

A peça encerrava-se ao som de palmas. O ator-médico, coordenador do $\mathrm{HL}$, então se levantou do chão e explicou o caso à plateia. Disse:

Doutora Nise, em 1944, chegou nesse hospício. Em algum ponto aconteceu essa cena, entre 1944 e 1946. Ela recusa apertar o botão do choque elétrico. A quantos de nós não é oferecido o botão para apertar o choque elétrico, todos os dias? Acusando o outro, negando o outro, não aceitando o outro. Não aceitar o outro é não aceitar a sua diferença!

Esta foi a primeira das muitas referências à médica que se desenrolariam ao longo do trabalho de campo, através de múltiplas linguagens. Em uma das mais marcantes visitas ao HL, já depois do término do Ocupa Nise, o médico-ator sugeriu que o hino do HL fosse cantado por todos. Uma boneca com a figura de Nise da Silveira, de mais ou menos três metros de altura, foi então trazida ao centro do salão de entrada, no segundo andar da antiga enfermaria. Explicava: "Nise da Silveira é o Galileu da medicina. O problema é que ela veio de longe, daqui do Engenho de Dentro". Uma certa melancolia emergia aqui, chamando a atenção para o despretígio das propostas da médica alagoana e o desconhecimento de sua trajetória. 
Este, no entanto, logo era contrabalançado pela glória da rebeldia. Naquela ocasião, todos se levantaram e, em clima de festa, entoaram uma melodia que se assemelhava a uma marchinha de carnaval: "Viva Nise da Silveira! Entre nessa brincadeira! Entre nessa brincadeira!".

Antes de sair do salão, ainda se podia encontrar no edifício uma pintura espetacular de Nise. Um stencil com os dizeres Dionise-se e o rosto da médica replicava-se ao longo da ocupação em referência conjunta à Nise e ao deus grego Dionísio. O culto à imagem da psiquiatra chamava a atenção aos olhos dos visitantes. Vibrante, o lugar diferenciava-se radicalmente do tom mais solene do MII, convidando todos à sua congregação. Por outro lado, assemelhava-se a este, na medida em que compartilhava uma mesma figura de devoção.

"Quem passar por essa porta será acolhido. A gente adoece junto e se cura junto", dizia Vitor Pordeus, cuja trajetória foi se revelando ao longo das atividades do HL. Se no MII a presença de Lula se unia à de uma equipe de ex-colaboradores da psiquiatra, no HL, Pordeus tinha um voo solo no empreendimento da memória da médica, embora com um público cativo e crescente, entre parceiros e aprendizes. Nascido no Rio de Janeiro em 1980, ele graduou-se em Medicina pela UFF, com especialização em imunologia. Realizou residência no Instituto Weizmann e na Universidad de Tel Aviv, em Israel. Em seguida, chegou a ingressar no doutorado em Saúde Pública da USP. A partir de um período de autoquestionamento que impossibilitou a conclusão do curso, concentrou suas atividades no campo artístico, sobretudo a partir de 2006, quando ingressou no grupo de teatro de rua Tá Na Rua, coordenado por Amir Haddad. Entretanto, não abandonou seu interesse pela produção de conhecimento e pela prática médica. Em 2008, enquanto trabalhava na divisão de pesquisa do Hospital Pró-Cardíaco, uma instituição privada do Rio de Janeiro, seu chefe recebeu indicação para ser secretário de Saúde do município. Graças a este contato, o médico e ator foi convidado para coordenar o Núcleo de Cultura, Ciência e Saúde, assumindo o cargo no ano seguinte.

Nessa época, Pordeus ainda não conhecia Nise da Silveira, nem o Engenho de Dentro. Incentivado por seus colegas de trabalho, começou a fazer suas primeiras visitas à instituição que levava o nome da psiquiatra alagoana. A reação foi impactante. Como afirmou uma das muitas reportagens sobre a biografia do médico carioca: "Eu cheguei lá e me apaixonei profundamente porque é uma revolução realmente o que a Dra. Nise fez, que foi justamente explorar o mundo interno dos ditos esquizofrênicos [...] Dra. Nise é a melhor médica da história do Brasil" (Pordeus 2014:s/p). 
Esse contato inicial foi travado com o material presente no MII. Entretanto, Pordeus jamais se filiou a esta instituição ou aos seus gestores, preferindo se orientar por uma direção própria e autodidata no estudo do referencial nisiano. Diferenciava-se, portanto, de outros produtores de memória oficiosa, como os do meio cinematográfico aqui citados, os quais faziam suas carreiras através daquelas já estabelecidas. Nesse sentido, em julho de 2012, o HL começou a ganhar forma dentro do complexo psiquiátrico do Engenho de Dentro. Nessas enfermarias se instalaram seis coletivos artísticos, que se tornaram os primeiros residentes. ${ }^{5}$ Além disso, foram abertos quartos ocupados com camas-beliche, destinadas a receber os participantes dos eventos e eventuais hóspedes. A estrutura contou ainda com uma cozinha, uma biblioteca e o hall de entrada, principal lugar de reuniões do coletivo. O projeto consolidou, assim, sua espacialidade, possibilitando o trânsito entre artistas, visitantes e pacientes internos e externos dentro do hospital.

Passei a frequentar constantemente o lugar nos meses que sucederam o Carnaval de 2015. Nesse período, estive presente nas oficinas de ação expressiva, atividades dramatúrgicas que contavam com a participação de pacientes psiquiátricos, agentes culturais de saúde, atores, terapeutas, estudantes de medicina, psicologia e artes visuais, voluntários e interessados em geral. As oficinas se desenvolviam no Chalé, espécie de pequena arena a céu aberto, situada em um terreno elevado no coração do complexo hospitalar. Era nesse mesmo espaço que, décadas atrás, os clientes de Nise encontravam ar fresco para pintar.

Mais que pintar ou modelar, porém, tratava-se ali de atuar. Nas bordas sinuosas da ágora, fantasias espalhavam-se pelo chão. Eram chapéus, vestidos, flores, penduricalhos e capas coloridas à espera de serem tomados por seus atores. Entrando e saindo do invólucro, Pordeus coordenava a música, que variava de balé clássico a funk carioca. Os recém-chegados precisavam apenas tomar algum adereço e engajar-se no movimento junto às outras pessoas. Tratava-se, assim, de um exercício teatral baseado na espontaneidade dos gestos e na configuração de cenas improvisadas. E Nise da Silveira, que havia caminhado ali, estava presente, assim como os grandes artistas que eram internos naquele hospital. "Ela nos olha, orgulhosa!", dizia o médico. Ninguém ali duvidava, a despeito da diferença do método. Embora práticas teatrais tenham estado presentes na obra de Nise, em seu trabalho havia maior repercussão da pintura e da modelagem enquanto atividades terapêuticas (Silveira 1992). 
Nise não era a única referência a habitar as práticas preconizadas na política pública. Seu nome se unia a Shakespeare, cuja peça Hamlet constituía um dos principais ensaios do coletivo, realizados semanalmente a partir de uma excursão à praça da Pedra do Arpoador, em Ipanema, usada como ágora teatral. Diversamente das oficinas de ação expressiva, esta atividade tinha um roteiro formal, embora nem sempre seguido à risca. A atividade chegou a ser registrada pela BBC de Londres, contribuindo para a repercussão midiática do HL. Ademais, destacam-se outras referências citadas por Pordeus em suas atividades educativas realizadas em sua maioria no próprio Instituto Nise, tal como Curso de Psicopatologia do Hotel da Loucura, que consistia em uma série de palestras abertas ao público em geral. Ali, nomes caros ao pensamento de Nise, como Jung e Spinoza, se uniam a referências acadêmicas inéditas, como o neurobiólogo Humberto Maturana. Via-se que o HL se abria às misturas, não se limitando exclusivamente à obra da médica. Além disso, evidenciava-se um esforço de tornar Nise uma referência propriamente científica. Ademais, diversamente do MII, seus atores eram reticentes quanto à continuidade do movimento mais amplo da $\mathrm{RP}$, preferindo ater-se à sua originalidade. Nesse sentido, simultaneamente à vangloriação de Nise, verificava-se ali uma leitura criativa de sua obra, e não simplesmente uma reprodução do status quo.

A repercussão do trabalho de Pordeus foi tamanha que, ao longo do desenvolvimento da pesquisa, repetidas vezes escutei aqueles que frequentavam suas atividades descrevendo-o como "o verdadeiro herdeiro da Nise", por levar adiante suas propostas com grande fervor. Embora fosse desconsiderado por parte de aalguns nisianos estabelecidos do MII, naquele contexto era visto quase como a própria reencarnação da psiquiatra em um corpo jovem, masculino e cheio de vida. "Ele é a Nise", diziam meus companheiros, fascinados com seu caráter.

Em meados de 2015, Pordeus deu início a um doutoramento no Departamento de Psiquiatria Cultural da McGill University, em Montreal, no Canadá, tendo que se ausentar do cotidiano do projeto para cumprir os requisitos da pós-graduação. Nunca deixou de se comunicar com sua equipe, e continuou a retornar com regularidade ao Rio de Janeiro, onde passou a desenvolver um novo projeto com uma peça baseada no Fausto, de Goethe. Entretanto, em maio de 2016, o médico e toda a rede do HL foram pegos de surpresa com a notícia da exoneração de seu cargo. A decisão foi silenciosamente publicada no Diário Oficial da União, enquanto ele se se encontrava em Montreal. A aparente justificativa para tal ato, surgida nas redes sociais, foi o descumprimento de sua carga horária e sua "ausência" nas atividades do projeto. Os defensores do projeto consideraram esse 
argumento desonesto, na medida em que o profissional estava dedicando seu tempo justamente a uma atividade destinada à aplicação do conhecimento produzido no HL.

As manifestações, no entanto, não foram suficientes para reverter a destituição. O território do HL permaneceu, transformando-se, porém, no Espaço Travessia - Corpo e Movimento. Pordeus foi substituído por outro profissional que não tinha relação prévia com o projeto, que teve que se rearticular por completo. O grupo diminuído, mas resistente, passou a realizar seus encontros fora do espaço hospitalar, na Praça Rio Grande do Norte, no Engenho de Dentro, a poucos metros do Instituto Nise. O ator-médico, que permaneceu com seu trabalho em Montreal, continuou em contato com eles, regressando de quando em quando ao Brasil.

Ao mesmo tempo, Pordeus lamentava-se pelo silêncio de outros profissionais vinculados ao trabalho de Nise da Silveira. Não houve nenhuma manifestação de apoio da parte da atual direção do Instituto Municipal Nise da Silveira ou do MII, ou tampouco da produção do filme O Coração da Loucura, que era lançado naquele momento. Sobre este ponto afirmava Vitor nas redes sociais: "Tivemos que encarar também o difícil e incompreensível silêncio de toda uma corte de ditos profissionais de saúde e nisianos, [...] silêncio, silêncio, silêncio, silêncio"... Assim como Nise havia sido alvo de diversas sabotagens ao longo de sua trajetória, o mesmo se passava agora com o jovem médico que buscava atualizar seus ensinamentos.

Esse silenciamento parece confirmar a problemática das disputas em torno da memória de Nise da Silveira. Por não ter convivido diretamente com a psiquiatra, e por trabalhar com suas ideias de uma forma criativa, inovadora, original - e, portanto, controversa, através de misturas impuras - Pordeus era considerado um herdeiro não tão legítimo e, desta forma, não despertava compaixão na maioria dos outros integrantes da trama nisiana.

\section{A modo de conclusão}

No período que sucedeu à morte de Nise da Silveira, construiu-se um estado da arte no qual os sujeitos foram imersos em um território móvel de produção da memória. Quando se perdeu a mediação da própria psiquiatra, abriu-se caminho a uma profusão de evocações que se condensaram em determinados lugares e personagens. Nesse sentido, a existência dessas contendas é acompanhada e ao mesmo tempo engendrada pela maior multiplicação da trama de atores, instituições e materialidades envolvida na vida e na obra da psiquiatra, que ocorre a partir da articulação entre o 
fenômeno já consolidado (constitutivo do que se chamou "memória oficial") e o incessante surgimento de novas produções culturais e políticas públicas desenvolvidas sob a égide do nome da médica, independentemente do seu grupo mais próximo de atores (ensejando a denominada "memória oficiosa"). Dois extremos dessa polarização foram expostos aqui, mas também suas posições intermediárias - a exemplo do filme Nise - O Coração da Loucura, uma memória oficiosa que se alimenta da oficial, extraindo daí sua validade.

Neste artigo, buscou-se demonstrar como o contato direto com o trabalho de Nise da Silveira durante seu tempo de vida opera como critério de legitimidade da evocação de seu nome. Dessa forma, quanto maior o atendimento a esse mandato, mais reconhecido é o ator; quanto menos, mais marginal - mas também mais criativo, possibilitando a atração de novos séquitos de interessados. Como propõe Pollak (2006), a memória prescinde da referência a acontecimentos e lugares experimentados diretamente, na medida em que se realizam transferências que podem ser reais ou projeções de outros eventos. Não obstante, o que se nota aqui é a existência de uma hierarquia atinente à conexão direta ou indireta com a vida e a obra da médica.

Ademais, essa diferença se inscreve no próprio espaço institucional habitado pelos atores sociais aqui referenciados. O MII consiste em um lugar que abriga as relíquias de Nise da Silveira, no sentido atribuído por Regina Abreu e Carmen Maschietto (2003). Trata-se de materialidades que, tendo pertencido de fato à personagem ou às pessoas de seu convívio, a evocam em uma relação metonímica, ensejando efeitos de autenticidade. Inclui-se aqui o espaço museal como um todo, fundado pela médica, assim como seus elementos particulares: os livros da biblioteca, herança do seu acervo privado; a mesa do grupo de estudos; suas imagens fotográficas, exibidas na mostra; as obras do ateliê que ela mesma monitorou... No HL, diversamente, a memória de Nise da Silveira se constitui através de alegorias. O compromisso com o original é rompido, e as relações são metafóricas. Verificam-se em representações teatrais, ou objetos evocativos, como a boneca da médica, seus stencils e imagens distribuídas pelas paredes da ocupação. Se o primeiro caso corresponde ao locus de consagração, por outro lado, como sugerem as próprias autoras, há no segundo um maior potencial de criação, onde novos elementos entram em cena.

A observação dessas tensões não é exclusiva deste campo em particular, mas diz respeito à própria especificidade dos saberes que se desenvolvem mais ou menos às margens da instituições acadêmicas e políticas oficiais, e que criam seus próprios espaços de formação, validação e organização. A respeito da psicanálise, Jane Russo (1999) sugere que seu grau de adesão 
se aproxima ao de uma conversão religiosa, na medida em que o estilo de formação é altamente personalizado e seu reconhecimento se dá a partir da autorização de seus pares. Em linha similar, Mauro Pasqualini (2016) observa elementos comuns tanto na psicanálise quanto no marxismo: o culto aos fundadores; o espírito de seita; e a tendência a incorrer em disputas intensas em torno da ortodoxia de determinados legados e da fidelidade a eles, em contradição com a audácia intelectual, a originalidade e a criatividade que igualmente os caracterizam. Isto implica particulares empecilhos para o estabelecimento de novas correntes que buscam reler autores tendo por base desdobramentos teóricos mais recentes, sendo porém desprovidas do contato pessoal com seus inspiradores e suas relíquias.

É também o caso do campo aqui investigado, no qual se verifica não uma psicanálise strictu sensu ou uma corrente política como o marxismo, mas um tipo de prática terapêutica realizada no serviço público de saúde através de atividades expressivas. Viu-se como a irrupção do novo (consubstanciada no HL) encontra dificuldades de legitimação diante de uma memória cristalizada na instituição fundada diretamente por Nise da Silveira e gestionada por seus colaboradores mais próximos. Esta tensão não diz respeito só ao privilégio do contato pessoal com o ídolo e suas materialidades, mas também às ortodoxias relativas a seu método de trabalho. Assim, como demonstrado aqui, a aplicação de atividades terapêuticas baseadas em exercícios dramatúrgicos, mais do que na pintura ou na modelagem, enseja a acusação de que estas possam ser ineficazes ou inapropriadas como mecanismos de promoção de saúde mental.

Não obstante, a despeito dessas tensões relativas à legitimidade ou ao método, observou-se a existência de uma narrativa compartilhada em relação à trajetória da médica - a exemplo da onipresente cena do eletrochoque, que se repete em todos os espaços de memória aqui citados. Em ambos os lugares, a biografia de Nise da Silveira tende a seguir um roteiro similar, sem grandes dissidências quanto a seus feitos, datas ou valores. É o lugar de enunciação, muito mais que o conteúdo narrativo, aquele que é alvo de disputas nesse campo. Nota-se, em comum, a persistência da imagem dramática do combate a uma medicina agressiva e ineficaz, que proporciona uma tensão entre o sofrimento e o tratamento, entre a violência e a cura, engendrando o mito de Nise.

Halbwachs (1990) já apontava para a importância dos afetos e da criação de uma comunidade afetiva para a contrução da memória coletiva, chamando a atenção para seu papel fundamental no desenvolvimento da solidariedade entre seus integrantes. No caso específico da memória de Nise da Silveira, pode-se entender esses elementos nos termos do que Didier 
Fassin (2011) define como sentimentos morais, isto é, aquelas emoções que conduzem nossa atenção para o sofrimento do outro, articulando afetos, valores, sensibilidade e altruísmo. Estes são constitutivos do que o autor chama de práticas coletivas de compaixão e vitimização dirigidas aos estratos menos favorecidos da sociedade. A imagem da rebeldia é assim associada a um fundo benevolente, que teria dado aos loucos abandonados no asilo a possibilidade de expressão através da tinta, do barro e do pincel. Favorece-se, assim, a continuidade de um ídolo cultuado, de uma figura quase messiânica de devoção, tanto nos círculos oficiais quanto nos oficiosos.

Esse panorama traz alguns questionamentos quanto às continuidades da produção da memória de Nise da Silveira no tempo presente, sobretudo no contexto recente da falência dos ideias reformistas e do retorno das políticas manicomiais (Magaldi 2018c). Trata-se aqui de apontar para uma arena de disputas em constante mutação. Nesse contexto, pode ser que surjam os limites desse regime de memória. Como recentemente lamentou um dos colaboradores de Nise da Silveira em sua rede social, por ocasião do dia que corresponderia ao seu $114^{\circ}$ aniversário: "Sinto saudade de Nise. Não a Nise da Silveira de hoje, mitológica, quase santificada. Mas a Nise real: com seu fino humor sarcástico, suas contradições, sua força em agir sempre de acordo com que pensa, sua violência e sua doçura".

Através dessa mudança de tom, poderiam ser verificadas algumas linhas de fuga deixadas pelos ensinamentos da médica. Linhas que podem não estar devidamente estabilizadas em planos nacionais ou em compêndios médicos, na grande política ou na ciência oficial, mas que, mesmo assim, emergem das práticas, da contingência dos acontecimentos, dos pequenos provisórios da luta diária, dos agenciamentos, afetos e territórios do serviço público, do inferno de seus papéis e das frestas de seus muros.

Recebido em: 21 de maio de 2018

Aprovado em: 11 de setembro de 2019

Felipe Magaldi possui graduação em Ciências Sociais pelo IFCS-UFRJ, mestrado em Antropologia pela UFF e doutorado em Antropologia Social pelo PPGAS-Museu Nacional-UFRJ. Atualmente é pós-doutorando no Instituto de Antropología de Córdoba/UNC-Conicet.

https://orcid.org/0000-0002-1905-5365

E-mail: femagaldi@gmail.com 


\section{Notas}

1 O eletrochoque, mais conhecido como eletroconvulsoterapia, consiste no dispêndio de descargas elétricas na região das têmporas através do uso de pequenos eletrodos. A lobotomia ou leucotomia é uma neurocirurgia realizada a partir do desligamento de fibras cerebrais com a introdução de hastes metálicas. A insulinoterapia consiste na indução em coma hipoglicêmico do paciente psicótico por mediação da administração de grandes doses de insulina (Melo 2009).

2 São exemplos a Medalha do Estado da Guanabara (1975), a Medalha de Mérito Oswaldo Cruz (1981), título Honoris Causa pela Universidade do Estado do Rio de Janeiro e pela Escola de Ciências Médicas de Alagoas (1988), o Prêmio Mulher 90 (1990) e a Medalha Chico Mendes (1993) (Mello 2014).

3 No Brasil, a referência aos projetos de questionamento da psiquiatria costumava estar circunscrita ao final da década de 1970 em diante, durante o declínio da ditadura militar (1964-1985) (Silva 2013). Alguns autores (Amarante 1995; Delgado 2011; Tenório 2002) definem a Reforma Psiquiátrica brasileira como o processo histórico que surgiu mais concretamente nesse período, quando se delineou a crítica conjuntural ao sistema nacional de saúde mental no bojo do Movimento de Trabalhadores em Saúde Mental (MTSM) e, simultaneamente, a crítica estrutural ao saber e às instituições psiquiátricas clássicas. Tais acontecimentos se desenvolveram principalmente com inspiração na experiência da psiquiatria democrática italiana. Seu traço principal foi o repto pela cidadania das pessoas em sofrimento psíquico, em oposição ao modelo manicomial. Esse processo se condolidou juridicamente no ano de 2001, com a promulgação da Lei 10.216, conhecida como Lei Paulo Delgado (ou, alternativamente, Lei da Reforma Psiquiátrica), que instituiu tanto a proteção jurídica aos sujeitos em sofrimento psíquico quanto o redirecionamento da assistência de saúde mental no país através dos serviços substitutivos de atenção psicossocial. A noção de "cliente" foi sugerida na prática de trabalho de Nise da Silveira para contornar o termo "paciente", que poderia denotar "passividade".

4 Entre esses, se destacaram Norte Comum, Coletivo Vô Pixá Pelada, Néctar, CRUA - Coletivo Criativo de Rua, TV Caiçara, Jornal ReOrganise e Coletivo AIA, além da sede da Universidade Popular de Arte Ciência, do Núcleo de Cultura, Ciência e Saúde e do Teatro de DyoNises. 


\section{Fontes}

BERLINER，Roberto. 2016. Entrevista concedida a Alex Alves. Cineresenhas. Disponível em: http://cineresenhas.com.br/2016/04/21/entrevista-com-roberto-berliner-diretor-de-nise-o-coracao-da-loucura/. Acesso em 08/12/2017.

CUNHA, Marcia Leitão. 2008. "Apresentação". In: Bernardo Carneiro Horta, Nise. Arqueóloga dos mares. Rio de Janeiro: Aeroplano.

GULLAR, Ferreira. 1996. Nise da Silveira: uma psiquiatra rebelde. Rio de Janeiro: Relume Dumará. HORTA, Bernardo Carneiro. 2008. Nise. Arqueóloga dos mares. Rio de Janeiro: Aeroplano.

MELO, Walter. 2007. "Maceió é uma cidade mítica: o mito da origem em Nise da Silveira". Psicologia USP (Impresso), v. 18:101-124.

MELLO, Luiz Carlos. 2014. Nise da Silveira: caminhos de uma psiquiatra rebelde. Rio de Janeiro: Automática Edições.

POMPEU E SILVA, José Otávio Motta. 2013. Nise da Silveira-Memória do

\section{Referências bibliográficas}

ABREU, Regina \& MASCHIETTO, Carmen Cecília Trovatto. 2003. "As coisas da Casa e as coisas da Rua: musealizações e ressignificações de objetos no contexto de comemorações euclidianas". Oficina do Inconfidência, Ouro-Preto-MG, ano 3, n. 2:165-178, dez.

AMARANTE, Paulo Duarte. 1995. Loucos pela vida - a trajetória da reforma psiquiátrica no Brasil. Rio de Janeiro: Fiocruz.
Saber. Vol. 14. Rio de Janeiro: Biblioteca Nacional.

PORDEUS, Vitor. 2014. "Hotel da Loucura". Entrevista concedida a Vicente Lou. Leros, abr. Diponível em: https://pt.slideshare.net/ grimbow/036-040-vitor-pordeus. Acesso em 08/12/2017.

SILVEIRA, Nise. 1979. Terapêutica Ocupacional: Teoria e Prática. Rio de Janeiro: Casa das Palmeiras. 1981. Imagens do Inconsciente. Rio de Janeiro: Alhambra. . 1992. O mundo das imagens. São Paulo: Ed. Ática.

. 1994. Entrevista concedida a Luiz Gonzaga Pereira Leal. Psicol. cienc. prof., Brasília, v. 14, n. 1-3:2-22.

VELOSO, Amanda Mont'Alvão. 2017. "Quem foi Nise da Silveira, a mulher que revolucionou o tratamento da loucura no Brasil". Huff Post Brasil, 27/01/2017. Disponível em: http://www.huffpostbrasil. com/2016/04/19/quem-foi-nise-da-silveira_n_9671732.html. Acesso em 07/12/2017.

BEZERRA Jr., Benilton. 1994. "De médico, de louco e de todo mundo um pouco: o campo psiquiátrico no Brasil dos anos oitenta". In: Reinaldo Guimarães \& Ricardo Tavares (orgs.), Saúde e sociedade no Brasil: anos 80. Rio de Janeiro: Relume-Dumará. pp. 171-191.

BOURDIEU, Pierre. 1996. "A ilusão biográfica". In: Janaina Amado \& Marieta de Moraes Ferreira, Usos e Abusos da História Oral. Rio de Janeiro: Fundação Getúlio Vargas Editora. 
CARVALHO, Sonia Maria Marchi \& AMPARO, Pedro Henrique Mendes. 2006. "Nise da Silveira: a mãe da humana-idade". Rev. Latinoam. Psicopat. Fun., IX, 1:126-147.

DELGADO, Paulo Gabriel. 2011. "Democracia e reforma psiquiátrica no Brasil". ciências \& saúde coletiva, Rio de Janeiro, v. 16, n. 12.

FASSIN, Didier. 2011. Humanitarian reason: a moral history of the present. Berkeley: University of California Press.

HALBWACHS, Maurice. 1990. A memória coletiva. Rio de Janeiro: Vértice.

HEINICH, Nathalie. 2010. "Pour en finir avec l'illusion biographique". L'Homme, 195-196:421-430.

JELIN, Elizabeth. 2002. Los trabajos de la memoria. Madri: Spaña Editores/ Século XXI.

LEGOFF, Jacques. 1984. Documento-Monumento. Lisboa: Imprensa Nacional.

L'ESTOILE, Benoît de. 2012. "Images des paradis perdus. Mythe des peuples premiers, photographie at anthropologie". Vibrant, v. 9, n. 12.

MAGALDI, Felipe Sales. 2014. Frestas Estreitas: uma etnografia no Museu de Imagens do Inconsciente. Dissertação de Mestrado em Antropologia, Programa de Pós-Graduação em Antropologia, Universidade Federal Fluminense.

. 2016. "Entre o Inconsciente e a Cidadania: arte e loucura na reforma psiquiátrica brasileira a partir de uma etnografia no Museu de Imagens do Inconsciente". Ponto Urbe, n. 18. . 2018a. Frestas Estreitas: uma etnografia no Museu de Imagens do Inconsciente. Rio de Janeiro: Autorgrafia. . 2018b. A Unidade das Coisas: Nise da Silveira e a genealogia de uma psiquiatria rebelde no Rio de Janeiro, Brasil. Tese de Doutorado em Antropologia Social), Programa de Pós-Graduação em Antropologia Social, Museu Nacional, Universidade Federal do Rio de Janeiro.

. 2018c. "Del Fuera Valencius al Fuera Quirino. La restauración conservadora en la Política Nacional de Salud Mental de Brasil (2015-2018)". Reviise - Revista de Ciencias Sociales y Humanas.

MELO, Walter. 2009. "Nise da Silveira e o Campo da Saúde Mental (19441952): contribuições, embates e transformações". Mnemosine , v. 5:30-52.

. 2007. "Maceió é uma cidade mítica: o mito da origem em Nise da Silveira. Psicologia USP (Impresso), v. 18:101-124.

NORA, Pierre. 1997. Les Lieux de Mémoire. Paris: Gallimard.

PASQUALINI, Mauro. 2016. Psicoanálisis y teoría social. inconsciente y sociedad de Freud a Zizek. Buenos Aires: Fondo de Cultura Económica.

POLLAK, Michael. 1989. "Memória, esquecimento, silêncio". Estudos Históricos, Rio de Janeiro, v. 2, n. 3. . 2006. "Memoria e Identidad Social". In: Memoria, olvido, silencio. La producción social de identidades frente a situaciones límites. La Plata: Ediciones Al Margen.

POMIAN, Krzysztof. 1887. "Les archives Du Trésor des chartes au Caran". In: Les Lieux de Mémoire, III. París: Gallimard.

RUSSO, Jane. 1999. "Uma leitura antropológica do mundo psi". In: Ana Maria Jacó Vilela; Fabio Jabur \& Heliana Conde Rodrigues (orgs.), Clio-psyché: Histórias da psicologia no Brasil. 1. ed.Rio de Janeiro: UERJ. pp. 67-74. 
SILVA, Martinho Braga. 2013. "O que a Reforma Psiquiátrica Brasileira produziu? Sobre tecnologias psicossociais e categorias antimanicomiais". R@U: Revista de Antropologia Social dos Alunos do PPGAS-UFSCAR, v. 5:57-68.

TENÓRIO, Fernando. 2002. "A Reforma Psiquiátrica Brasileira, da Década de 1980 aos Dias Atuais: História e
Conceitos". In: História, Ciências, Saúde-Manguinhos (Impresso), v. 9:25-59.

VILLAS-BÔAS, Glaucia. 2015. "Arte, ciência e psiquiatria: o projeto de Nise da Silveira". In: Gilberto Hochman \& Nísia Trindade (orgs.), Médicos Intérpretes do Brasil. São Paulo: Hucitec Editora. 


\section{DAS MEM ÓRIAS DE \\ NISE DA SILVEIRA NO \\ HOSPITAL PSIQUIÁTRICO DO ENGENHO DE DENTRO}

Resumo

Este artigo consiste em um estudo sobre a construção da memória da psiquiatra alagoana Nise da Silveira (1905-1999), conhecida a partir da década de 1940 por sua luta contra intervenções biomédicas consideradas violentas e pela defesa de atividades expressivas (sobretudo pintura e modelagem) como forma de tratamento em saúde mental. Concentra-se aqui em projetos desenvolvidos atualmente no âmbito do Instituto Municipal Nise da Silveira, complexo hospitalar centenário localizado no bairro do Engenho de Dentro, no Rio de Janeiro, com ênfase no Museu de Imagens do Inconsciente, no Hotel da Loucura e seus respectivos líderes. Através de trabalho de campo, aponta-se para uma hierarquia de legitimidade concernente ao contato pessoal com a médica, na qual se inscreve uma tensão entre uma memória oficial e uma memória oficiosa.

Palavras-chave: Nise da Silveira; Memória social; Reforma psiquiátrica; Psicanálise; Saúde mental.

\author{
ON THE MEMORIES OF \\ NISE DA SILVEIRA IN THE \\ PSY CHIATRIC HOSPITAL OF \\ ENGENHO DE DENTRO
}

\section{Abstract}

This article studies the construction of the memory of the Alagoas-born psychiatrist Nise da Silveira (19051999), reknown since the 1940s for her struggle against biomedical interventions considered violent and for the defense of expressive activities (mainly painting and modeling) as a form of mental health treatment. It focuses on projects currently developed at the Nise da Silveira Mental Health Institute, a centennial hospital complex located in the district of Engenho de Dentro, in Rio de Janeiro, emphasizing the Museum of Images of the Unconscious, the Madness Hotel and their respective leaders. Through fieldwork, it reveals a hierarchy of legitimacy concerning personal contact with the physician, which inscribes a tension between an official memory and an unofficial memory.

Keywords: Nise da Silveira; Social memory; Psychiatric reform; Psychoanalysis; Mental health. 
DE LAS MEMORIAS DE

NISE DA SILVEIRA EN EL

HOSPITAL PSIQUIÁTRICO DE

ENGENHO DE DENTRO

\section{Resumen}

Este artículo consiste en un estudio sobre la construcción de la memoria de la psiquiatra Nise da Silveira (1905-1999), oriunda del Estado de Alagoas, conocida a partir de la década de 1940 por su lucha contra intervenciones biomédicas consideradas violentas y por la defensa de actividades expresivas (sobre todo pintura y modelado) como forma de tratamiento en la salud mental. Se centra aquí en proyectos desarrollados actualmente en el ámbito del Instituto Municipal Nise da Silveira, complejo hospitalario centenario ubicado en el barrio del Engenho de Dentro, en Río de Janeiro, con énfasis en el Museo de Imágenes del Inconsciente, en el Hotel de la Locura y sus respectivos líderes. A través de trabajo de campo, se apunta a una jerarquía de legitimidad concerniente al contacto personal con la médica, en la que se inscribe una tensión entre una memoria oficial y una memoria oficiosa.

Palabras clave: Nise da Silveira; Memoria social; Reforma psiquiátrica; Psicoanálisis; Salud mental. 